\title{
Siderophores Detection by using Blue Agar CAS Assay Methods
}

\author{
K. Srimathi ${ }^{{ }^{*}}$, H. Ann Suji ${ }^{2}$ \\ ${ }^{1,2}$ Annamalai University, Parangipettai, Tamil nadu
}

Available online at: www.isroset.org

Received: 06/Dec/2018, Accepted: 20/Dec/2018, Online: 31/Dec/2018

\begin{abstract}
The low iron molecules produced from various sources are the siderophores. These are taken up by bacteria to help their process of iron uptake which is necessary for all microbes to obtain environmental iron indeed for important processes. In the present study, siderophore production by bacteria present in the coastal waters of Parangipettai was analyzed. Among the total of 40 isolates obtained, only five were able to produce siderophores by the CAS agar plate assay method. The production of an orange or a yellow hallow zone around a colony indicated that it is a siderophore producer. The present study provides a detailed protocol to prepare the CAS agar without any difficulty.
\end{abstract}

Keywords: Siderophores, ferric iron, Bacillus, Pseudomonas.

\section{INTRODUCTION}

Numerous understudy lab ventures depend on the separation, distinguishing proof, and arrangement of microscopic organisms from natural or on the other hand different sources. One noteworthy zone of enthusiasm for arrangement of microscopic organisms is the ownership of destructiveness factors. Numerous microscopic organisms use siderophores to encourage the procedure of ferric iron take-up in the earth. This procedure can be found over every one of the three areas and is important for some microorganisms to get the ecological iron required for basic procedures. Siderophore creation can likewise be a main consideration in the capacity of pathogens to cause ailment since free iron is extremely constrained and frequently firmly bound to numerous proteins, for example, hemoglobin, transferrin, furthermore, lactoferrin (6).

Siderophores are ordered by the ligands used to chelate the ferric iron. These incorporate catecholates, hydroxamates, and carboxylates (6). Different tests have been created to distinguish distinctive phenotypes of siderophores (2-4). While these examines are helpful for distinguishing different siderophores, various examines would need to be performed to identify every conceivable type of siderophores. Schwyn and Neiland $(8,9,10)$ built up a general siderophore examine utilizing chrome azurol- S(CAS) and hexadecyltrimethylammonium bromide (HDTMA) as pointers. HDTMA has a moderate wellbeing and contact rating. Suitable individual defensive gear ought to be utilized. The CAS/ HDTMA binds firmly with ferric iron to deliver a blue shading. At the point when a solid iron chelator, for example, a siderophore expels press from the color complex, the shading changes from blue to orange.

\section{PROCEDURE:}

\subsection{General methods}

All chemical reagents were purchased from Aldrich, LOBA Chemicals. All glassware was rinsed in distilled water and ethanol prior to use and used without further purification.

\subsection{Sample Collection}

The Marine water sample was collected from sea shore of Parangipettai, Tamil nadu state, south cost of India. The sample was collected in sterile tube and brought to the laboratory.

\subsection{Bacterial isolation}

The sample was serially diluted in sterile sea water and an aliquot $(100 \mu \mathrm{l})$ was spread plated on Zobell Marine Agar. The plates were incubated at $30^{\circ} \mathrm{C}$ for $48-72 \mathrm{~h}$. Single colonies were picked and purity was confirmed by repeated streaking. The purified bacterial cultures were maintained on Zobell marine agar slants and these bacteria were further used for the detection of siderophores. 


\subsection{Identification of Siderophore Positive Cultures}

The Universal chrome azurol sulfonate (CAS) test was utilized to recognize siderophores, created by the microbes [7]. The sea water sample inferred bacterial isolates (SP1, SP2, SP3, SP4 and SP5) were spotted on CAS agar plates and incubated for $48 \mathrm{~h}$. After incubation period, spots were watched for colour change, assuming any.

\subsection{Detailed Procedure of CAS-Agar Preparation:}

The following is a detailed, well ordered methodology taken from Schwyn and Neilands (8). Setting up the CAS a gar can be a repetitive and troublesome process. By giving a point by point convention for doing this, we want to decrease the trouble.

All glassware washed with $6 \mathrm{M} \mathrm{HCl}$ to expel any follow components and were rinse with distilled water.

\section{A. Blue Dye:}

a. Solution 1:

I. $0.06 \mathrm{~g}$ of CAS (Loba Chemicals) was dissolved in $50 \mathrm{ml}$ of dd.

\section{b. Solution 2:}

I. $0.0027 \mathrm{~g}$ of $\mathrm{FeCl} 3-6 \mathrm{H} 2 \mathrm{O}$ was dissolved in $10 \mathrm{ml}$ of $10 \mathrm{mM} \mathrm{HCl}$.

\section{c. Solution 3:}

I. $0.073 \mathrm{~g}$ of HDTMA was dissolved in $40 \mathrm{ml}$ of ddH2O.

d. Solution 1 was blended with $9 \mathrm{ml}$ of Solution 2. It was then blended with Solution 3. Solution was then a blue shading. Then it was autoclaved and stored in a plastic holder/bottle.

\section{B. Mixture Solution:}

\section{a. Minimal Media 9 (MM9) Salt Solution Stock}

I. $15 \mathrm{~g} \mathrm{KH} 2 \mathrm{PO} 4,25 \mathrm{~g} \mathrm{NaCl}$, and $50 \mathrm{~g} \mathrm{NH} 4 \mathrm{Cl}$ were dissolved in $500 \mathrm{ml}$ of ddH2O.

\section{b. $20 \%$ Glucose Stock}

I. $20 \mathrm{~g}$ glucose was broken down in $100 \mathrm{ml}$ of ddH2O.

\section{c. $\mathrm{NaOH}$ Stock}

I. $25 \mathrm{~g}$ of $\mathrm{NaOH}$ was dissolved in $150 \mathrm{ml} \mathrm{ddH} 2 \mathrm{O}(\mathrm{pH}=12)$.

\section{d. Casamino Acid Solution}

i. $3 \mathrm{~g}$ of Casamino corrosive was dissolved in $27 \mathrm{ml}$ of ddH2O.

ii. It was then with 3\% 8-hydroxyquinoline in chloroform to evacuate any trace iron.

iii. Finally, it was filter sterilize.

\section{CAS agar Preparation:}

a. $100 \mathrm{ml}$ of MM9 salt solution was added to $750 \mathrm{ml}$ ofddH2O.

b. 32.24 g piperazine-N, N'-bis(2-ethanesulfonic acid) PIPES were dissolved.(PIPES will not dissolve below $\mathrm{pH}$ of 5).

i. The $\mathrm{pH}$ was brought up to 6 and slowly PIPES was added while stirring. There was a drop in PIPES while dissolve. While stirring, slowly bring the $\mathrm{pH}$ is brought to 6.8 slowly. A pH of medium should not be exceed 6.8 as this will turn the solution green.

c. $15 \mathrm{~g}$ of Bacto agar was added.

d. It was then autoclaved and cooled to $50^{\circ} \mathrm{C}$. 
e. $30 \mathrm{ml}$ of sterile Casamino acid solution and $10 \mathrm{ml}$ of sterile $20 \%$ glucose solution was added to MM9/PIPES mixture.

f. $100 \mathrm{ml}$ of Blue Dye solution was added slowly along the glass wall with enough agitation to mix thoroughly.

g. Aseptically the media was poured into plates.

\section{RESULT}

Siderophores are low molecular weight chelating specialists very synthesized by microorganism for their fitness of ferric iron in ferric hydroxide complex. They have incredible applications in plant development advancements, biocontrol action, and a few other ecologi-cal factors. They likewise indicate points of interest in the field of medication as a potential medication for the iron inadequate infections and goes about as against microbial specialists [11]. The distinct siderophore-producing bacterial isolates were screened out by performing CAS test (both subjectively and quantitatively).

In the present study, marine water samples from the Parangipettai coast water were processed to obtain siderophore producing bacterial isolates. A total of 40 isolates were obtained. However, only 5 isolates were identified as, the siderophores producing organisms by CAS agar plate assay methods. The orange hallow zone around the colony of the positive isolates were measured and tabulated (Table 2).

The detection of siderophores was confirmed by plating that all bacterial isolates in the CAS agar plate method. It was found only five bacterial isolates were showing distinct zone with the appearance of orange color ( Fig. 2 ) indicating the production of siderophore. Orange zone appearance clearly demonstrates siderophore production.(12)

The CAS or HDTMA forms a tight unpredictable with the ferric particle to make a blue shading in the medium, and when the iron chelators like the siderophores are added to the medium, it expels the iron from the color complex and the shading eventually changes from blue to orange [13]

\section{Isolation of bacteria}

The total viable count of bacterial colonies recorded in marine water sample was $191 \times 102 \pm 0.23 \mathrm{CFU} / \mathrm{g}$ in $10^{-1} \mathrm{dilution}$ and $43 \times 106 \pm 0.13 \mathrm{CFU} / \mathrm{g}$ in $10^{-5}$ dilution (Table.1).

Table.1 Total viable counts of bacterial colonies at different dilutions.

\begin{tabular}{|c|c|c|}
\hline Sl.No & Dilution & Number of colonies (CFU/g) \\
\hline 1. & $10^{-1}$ & $191 \times 10^{2}$ \\
\hline 2. & $10^{-2}$ & $135 \times 10^{3}$ \\
\hline 3. & $10^{-3}$ & $112 \times 10^{4}$ \\
\hline 4. & $10^{-4}$ & $79 \times 10^{5}$ \\
\hline 5. & $10^{-5}$ & $43 \times 10^{6}$ \\
\hline
\end{tabular}

\section{Screening for siderophore production}

Siderophore producing bacterial isolates and zone size from CAS agar plate assay was given in table. 2

Table 2. Siderophore production by the identified bacterial strains.

\begin{tabular}{|c|c|c|c|}
\hline $\begin{array}{c}\text { Culture. } \\
\text { No }\end{array}$ & Bacterial strains & $\begin{array}{c}\text { Siderophore Production } \\
\text { (Zone formation) }\end{array}$ & Zone size \\
\hline S1 & Bacillus $s p$. & + & $0.4 \mathrm{~mm}$ \\
\hline S2 & Bacillus $s p$. & + & $0.3 \mathrm{~mm}$ \\
\hline S3 & Pseudomonas $s p$. & + & $0.11 \mathrm{~mm}$ \\
\hline S4 & Pseudomonas $s p$. & + & $0.5 \mathrm{~mm}$ \\
\hline S5 & Pseudomonas $s p$. & + & $0.4 \mathrm{~mm}$ \\
\hline
\end{tabular}

$+=$ positive enzyme activity 


\section{Identification of bacteria}

Based on the morphological, physiological and biochemical and characteristics, Bacillus sp. and Pseudomonas sp. of bacteria were identified (Table.3).

Table 3. Morphological, physiological, biochemical characteristics of the identified bacterial strains.

\begin{tabular}{|c|c|c|c|c|c|c|c|c|c|c|c|c|c|c|c|c|}
\hline$\stackrel{\ominus}{\mathbf{Z}^{\prime}}$ & $\stackrel{\Xi}{\stackrel{\Xi}{\Xi}}$ & 预 & 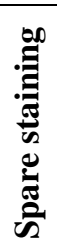 & $\underset{N}{\sim}$ & 帝 & 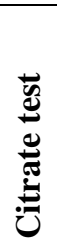 & $\frac{ت}{\stackrel{D}{d}}$ & 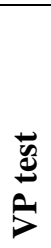 & Dू. & ڤ્. & $\frac{0}{\frac{0}{\theta}}$ & 总 & 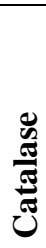 & : & $\vec{D}$ & Identified organisms \\
\hline 1. & S.1 & $\mathrm{G}(+)$ rods & + & - & - & - & - & + & - & - & - & - & + & + & $\mathrm{K} / \mathrm{A}$ & Bacillus sp. \\
\hline 2. & S.2 & $\mathrm{G}(+)$ rods & + & - & - & - & + & + & - & + & + & - & + & + & $\mathrm{K} / \mathrm{A}$ & Bacillus sp. \\
\hline 3. & S.3 & $\mathrm{G}(+)$ rods & - & - & + & + & - & - & - & - & + & + & + & - & $\mathrm{K} / \mathrm{A}$ & Pseudomonas sp. \\
\hline 4. & S.4 & $\mathrm{G}(-)$ rods & - & - & + & + & - & - & - & - & + & + & + & - & $\mathrm{K} / \mathrm{A}$ & Pseusomonas sp. \\
\hline 5. & S.5 & $\mathrm{G}(-)$ rods & - & - & + & + & - & - & - & - & + & + & + & - & $\mathrm{K} / \mathrm{A}$ & Pseudomonas sp. \\
\hline
\end{tabular}

+= Positive; - = negative ; K/A= Alkaline slant/ acid butt; and K/K Alkaline slant/ alkaline butt

Fig 1. Blue dye (CAS reagent)

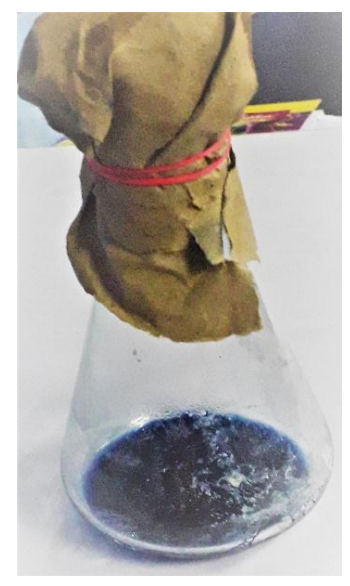

Fig 2. Siderophore production by isolated bacteria in CAS agar medium

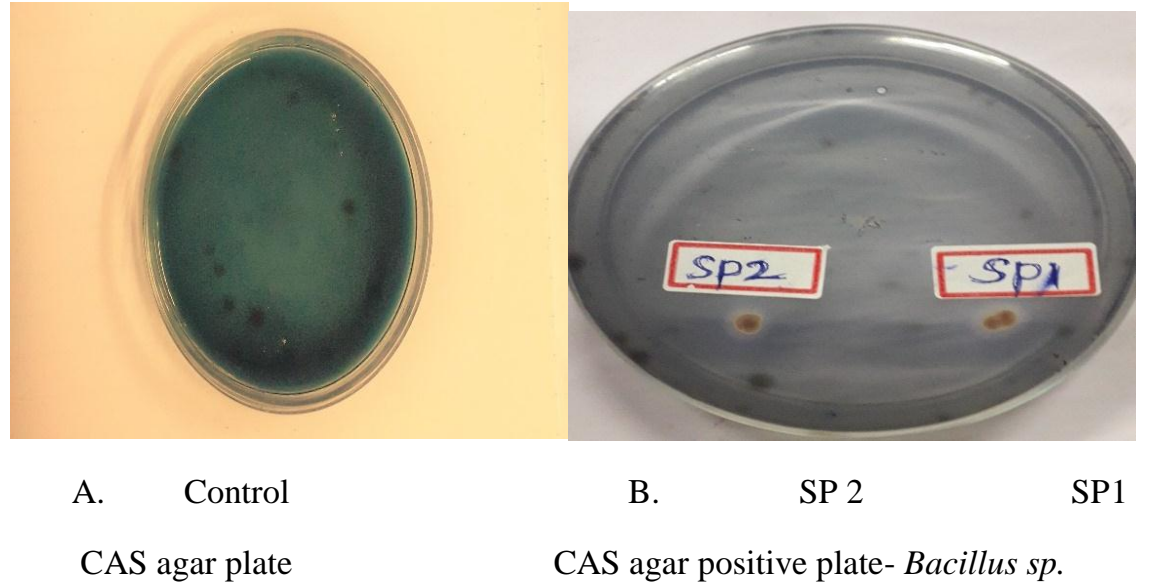




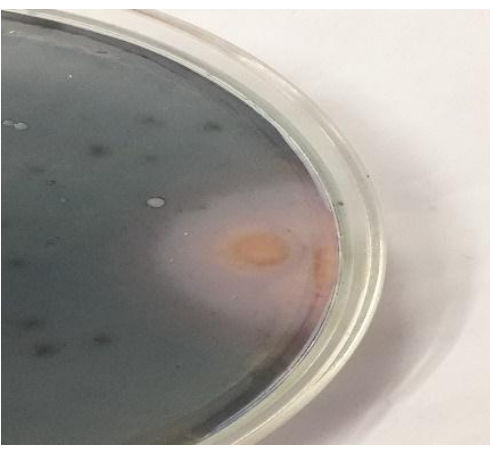

C. $\quad$ SP3

CAS agar Positive plate-Pseudomonas sp.

The appearance of orange color and zone formation indicating siderophore production in CAS agar plate assay.

\section{DISSCUSION}

Since this media is extremely delicate to varieties in $\mathrm{pH}$ or $\mathrm{FeCl} 3$ fixations, it might be valuable to play out a quality control test preceding utilizing the plates in the lab. A chelation change test can be performed on one plate of a cluster. Earlier to this test, it is critical to outwardly recognize that the media has a blue shading to it. $\mathrm{pH}$ can change the shade of the CAS/ Fe complex keeping the CAS from changing shading with the evacuation of the iron. On the off chance that the plate shows up excessively blue, at that point a fitting of the media is expelled. This can be accomplished utilizing a sterile $1 \mathrm{ml}$ micropipette tip took care of aseptically. The turnaround (huge opening) end is squeezed into the agar at that point tilted up to expel a roundabout attachment of the media. The well in the media made by the expulsion of this fitting is loaded up with a soaked arrangement of 8-hydroxyquinoline. Inside a couple of minutes, an orange radiance ought to show up as the 8hydroxyquinoline arrangement diffuses in the agar.

CAS agar plates are valuable in the distinguishing proof of siderophores in Gram-negative microbes, however HDTMA (HexaDecyltrimeThylammonium Bromide), in high fixations, is harmful to Gram-positive microscopic organisms and growths. Various changed CAS (Chrome azurol S) measures have been produced to take into account the development of these life form $(1,5,7,9$ and 10).

Generally speaking, CAS plates give a moderately simple to-utilize specific and differential media that can be incorporated into most microbiology research center.

\section{ACKNOWLEDGMENT}

The authors thank the SERB New Delhi for financially supporting the present research work. They also thank the Annamalai University for providing the facilities required to do the work successfully.

\section{REFERENCE}

[1]. Ames-Gottfred, N. P., B. R. Christie, and D. C. Jordan. 1989. Use of the Chrome Azurol S agar plate technique to differentiate strains and field isolates of Rhizobium leguminosarum biovar trifolii. Appl. Environ. Microbiol. 55:707-710.

[2]. Arnold, L. D., and T. Viswanatha. 1983. The use of bis(mercaptoacetato-S,O)hydroxoiron(III) complex for the determination of hydroxamates. J. Biochem. Biophys. Methods 8:307-320.

[3]. Arnow, L. E. 1937. Colorimetric determination of the components of 3,4 Dihydroxyphenylalaninetyrosine mixtures. J. Biol. Chem. 118:531537.

[4]. Atkin, C. L., J. B. Neilands, and H. J. Phaff. 1970. Rhodotorulic acid from species of Leucosporidium, Rhodosporidium, Rhodotorula, Sporidiobolus, and Sporobolomyces, and a new alanine-containing ferrichrome from Cryptococcus

[5]. melibiosum. J. Bacteriol. 103:722-733.

[6]. Machuca, A., and A. M. Milagres. 2003. Use of CAS agar plate modified to study the effect of different variables on the siderophore production by Aspergillus. Letters Appl.Microbiol. 36:177-181.

[7]. Miethke, M., and M. A. Marahiel. 2007. Siderophore based iron acquisition and pathogen control. Microbiol.Molecul. Biol. Rev. 71:413-451. 
[8]. Pérez-Miranda, S., N. Cabirol, R. George-Téllez, L. S. Zamudio-Rivera, and F. J. Fernández. 2007. O-CAS, a fast and universal method for siderophore detection. J. Microbiol. Methods 70:127-131.

[9]. Schwyn, B., and J. B. Neilands. 1987. Universal chemical assay for the detection and determination of siderophores. Analytical Biochem. 160:47-56.

[10]. Paulo Teixeira Lacava, Maria Estela Silva-Stenico, Welington Luiz Araújo, Ana Valéria Colnaghi Simionato. 2008. Detection of siderophores in endophytic bacteria Methylobacterium spp. associated with Xylella fastidiosa subsp. Pauca. Pesq. agropec. bras., Brasília, v.43, n.4, p.521528 ,

[11]. Julie Granger1 and Neil M. Price .1999. The importance of siderophores in iron nutrition of heterotrophic marine bacteria. Limnol. Oceanogr., 44(3), 541-555. 1999, by the American Society of Limnology and Oceanography, Inc.

[12]. K. Postle .1990. Aerobic regulation of the Escherichia coli tonB gene by changes in iron availability and the fur locus, J. Bacteriol. 172:22872293 .

[13]. S.K. Ghosh, S. Pal, N. Chakraborty. 2015. The qualitative and quantitative assay of siderophore production by some microorganisms and effect of different media on its production, Int. J. Chem. Sci. 13 1621-1629.

[14]. B.C. Louden, D. Haarmann, A. Lynne, Use of blue agar CAS assay for siderophore detection, J. Microbiol. Biol. Educ. 12 (2011) 51-53, doi: 10.1128/ jmbe.v12i1.249. [25] M.K. Solanki, R.K. 